Special Issue of the 6th International Congress \& Exhibition (APMAS2016), Maslak, Istanbul, Turkey, June 1-3, 2016

\title{
Fume Formation Rate Analysis of Shipbuilding Steel with SMAW Using Taguchi Design and ANOVA
}

\author{
T. $\operatorname{MERT}^{a, *}$ AND S. EKINCI ${ }^{b}$ \\ ${ }^{a}$ Yildiz Technical University, Department of Mechanical Engineering, 34349 Istanbul, Turkey \\ ${ }^{b}$ Yildiz Technical University, Department of Naval Architecture and Marine Engineering, 34349 Istanbul, Turkey
}

Shipbuilding industry grows rapidly due to the increasing growth of economies and thus, the need for new and bigger ships emerge. Manufacturing of ships in shipyards includes harmful processes, such as welding, which impact the workers and the environment. As a consequence of increase in demand for new ships, deleterious welding fume and emissions all over the world increase year by year. Welding fume includes hazardous micro and sub-micro sized metal particulates and in addition to welding fume, welding emissions consist of detrimental gaseous wastes as well. In this study, a set of experiments was designed by Taguchi method. These experiments were realized by two welders using two different types of covered electrodes (rutile and cellulosic), welding speeds and currents on Grade A shipbuilding steel, which is one of the most common steels in shipbuilding. After the experiments, fume formation rate was measured and it was observed that the contributions of the factors are $92.47 \%, 5.42 \%$ and $1.66 \%$ for electrode type, current and welder, respectively. The results were assessed using Taguchi and ANOVA and evaluated in terms of environment and occupational health and safety.

DOI: 10.12693/APhysPolA.131.495

PACS/topics: $81.20 . \mathrm{Vj}$

\section{Introduction}

General economic growth of the world has a close relationship with the total world trade and shipping. Shipping activities run approximately $90 \%$ of total world trade [1]. Total world fleet has increased approximately $5.5 \%$ annually between 2000 and 2015 . The total dead weight ton (DWT) of all fleet is estimated to be 1734561367 [2]. Ship manufacturing methods are mainly based on joining processes, such as welding. Welding is one of the most important emission sources during ship manufacturing. Although there are various types of welding, shielded metal arc welding (SMAW), gas metal arc welding, submerged arc welding and plasma arc welding are the most common welding methods used in ship building [3]. An emission estimation approach was developed for the tankers manufactured in the world during 2012 and 2013, and according to this approach, it is concluded that approximately 3500 tons of harmful welding fume was emitted into the atmosphere just from the operation of SMAW of tankers, manufactured in the year of 2012 [4]. Arc welding processes form noxious particles in the size range of $0.005-20 \mu \mathrm{m}$, which may cause hazard in terms of health and environment. These particles are referred to as welding fume [5].

Various fumes and gases can be generated during welding. Aerosols, which are formed as a result of complex vaporization-condensation-oxidation processes and include metal particles, are the main by-product of welding process [6]. The area of deposition of the particles in the respiratory tract strongly depends on the particles'

*corresponding author; e-mail: tmert@yildiz.edu.tr shape and size. Besides, the particles' density, size and shape play an important role on the biological activity of the welding fume [5]. Metal cutting and welding, which are major emission sources, are highly utilized in shipyards. Metal cutting generates air emissions, which contain heavy metals, oxides of nitrogen, metal ions, carbon monoxide, carbon dioxide and ozone [7]. Welders may work in poorly ventilated confined spaces in shipyards. The potential hazards of welding operations include metal fumes, toxic gases, ultraviolet and infrared radiation [8].

Mener et al. [9] have included a survey to identify typical welding procedures conducted at shipyards for development of an emission factor test plan, implementation of the test plan, and development of emission factors. Pires et al. [10] have researched seven shielding gas mixtures and the influence of these mixtures on the process characteristics, namely on the metal transfer modes and fume emissions. Deam et al. [11] have investigated metal droplet size and wire feed speed control on the fine fume formation rate (FFR) and have developed metal vapor mechanism for fume formation. Serageldin and Reeves [12] have investigated procedures developed for deriving welding emission factors that can be used for performing the residual risk analysis. Welding is highly associated with fume formation, which is not only harmful to worker's health, but also to the environment. The workers are exposed to fumes and gases which may be hazardous for their health. Welding fume particles less than $1 \mathrm{~mm}$ in diameter constitute the greatest health hazard, because of their ability to penetrate deep into the lungs, and because they are not readily cleared by the cilia, lining the respiratory tract [13].

The chemical composition of welding fumes can be quite complex. Fumes emitted from welding of different 
types of steels may contain iron, manganese, silica, chromium, nickel and copper [14]. The emissions of toxic air contaminants, such as manganese, nickel, chromium, cobalt and lead during welding have potential adverse human health impacts [9]. Manganese oxide is used as a flux agent in the coatings of shielded metal arc electrodes, in the flux-cored arc electrodes, and as an alloying element used in electrodes. Some special steels containing high manganese content may produce a high concentration of manganese oxide in the fume and manganese has been shown to be both a cytotoxic and neurotoxic substance. Exposure to high levels of Mn causes neurological disorders in workers, involved in the mining and processing of manganese ores [14]. In addition, it has been observed that exposure to high levels of pure manganese may cause a refractory neurological condition named as manganism.

The tumorigenicity effect of the specific welding fume is investigated incipiently by using lung tumor susceptible and tumor-resistant mouse strains [15]. A wellrecognized, the occupational disease of the central nervous system, resembling Parkinson's disease, is a distinctive manifestation of chronic manganese poisoning [16]. Neurotoxicity of manganese has been observed under existing conditions of occupational settings, where the possibility exists for chronic inhalation exposure to high levels of manganese or following the accidental ingestion of large quantities of manganese [17]. Many welders experience bronchitis, metal fume fever, lung function changes, and an increase in the incidence of lung infection. Mainly respiratory irritation and related effects, few chronic, long-term effects have been directly attributed to welding fumes and gases [4]. Some type of respiratory disorder occurs during long-time employment of welders. The effect of welding fumes on human health is understood better by the help of the studies on animal models and the ability to control the welding fume exposure in toxicology [18].

Due to the insufficient data on toxicological and epidemiological effects of welding fume, determining a doseresponse relationship for subclinical or clinical neurotoxicity and exposure to manganese is relatively difficult. Additionally, welder exposure to different forms of manganese in different occupational conditions must be investigated and understood clearly in terms of toxicokinetics [17].

Chromium and nickel have been classified as human carcinogens [4, 14]. Additionally, the hexavalent form of chromium $(\mathrm{Cr}(\mathrm{VI}))$ is also found in some welding fume emissions and it has been designated as an important pollutant, because of its potential to cause genetic mutations on mammal cells and as a result, the cancer [19, 20]. Matczak and Chmielnicka [21] have demonstrated that reduction of sodium and potassium in manual metal arcwelding electrodes leads to substantial reductions in $\mathrm{Cr}$ (VI) concentrations in the fume as well as a reduction in the fume formation rate. Health aspects associated with welding and cutting are quite important and the industry is continuing its research, to evaluate the welder's exposure to welding fumes and gases and their effects of on health and on climatic changes [6].

According to the study of Park et al. [22], in which the authors examine an episode of confined space welding, where initially, there was inadequate protection and ventilation according to workers, state regulatory authorities and an independent contractor performing air monitoring, it was indicated that the goal of risk assessment is often to estimate excess lifetime risk for some disabling or fatal health outcome in relation to a fixed workplace exposure, lasting a working lifetime. Welding fume formation rate and chemical composition of the particles are affected by welding parameters and application variables. Welding fume formation rate is affected by the following factors; welding process type, current type, current, varying voltage depending on the length of the arc, welding position, the angle between the electrode and the work piece, heat input, chemical composition of the work piece, chemical composition of the filler metal, work piece surface condition and "shielding gas.

In this study, SMAW of shipbuilding steel was realized with rutile and cellulosic covered electrodes using a variety of parameters. After the experiments, fume accumulation was measured and FFR was calculated. The results were evaluated using Taguchi design of experiment and analysis of variance. In the literature, the authors, so far, have not encountered such an analysis on fume formation using Taguchi method applied to shipbuilding industry. Results were evaluated with regard to occupational health and safety, as well as environmental effects. Furthermore, exposure to burrs, flames, sparks, toxic fumes and dusts occurring during welding and allied processes may cause injuries or occupational accidents and diseases that result in workforce loss during working days [23].

\section{Experimental study}

Taguchi method has been developed by Genichi Taguchi to improve the performance and quality of manufactured products [24]. In this study, experiments were designed using Taguchi method, which is one of the most reliable designs of experiment methods [25]. Taguchi design of L8 orthogonal array was implemented and welding trials were run for three times. Table I shows four process factors (i.e. welder, electrode type, welding speed and current) and two levels, which were used to form L8 orthogonal array. Fume emission experiments have been realized inside a fume chamber, designed according to EN ISO 15011-1:2009 [26], with two different welders, in order to observe the effect of welder on fume formation. Round plates of grade A ship building steel, with diameter of $290 \mathrm{~mm}$, were used in the experiments. These plates were welded with rutile (EN ISO 2560-A: E 420 RR 12) and cellulosic (EN 499: E 383 C 21) covered electrodes with $3.20 \mathrm{~mm}$ diameter for 45 seconds. Welding power source was Lincoln Electric Invertec V260-S. Chemical composition of base metal and the electrodes is given in Table II. Fume was captured on round Sartorius 
MGA glass fiber filters with $240 \mathrm{~mm}$ diameter. Sampling had lasted for a total of 5 minutes. Filters were stored in a furnace at $110^{\circ} \mathrm{C}$ for at least 1 hour before and after the experiments. Shimadzu BL-320H electronic balance was used to weigh filters and electrodes.

TABLE I

Experimental factors and levels.

\begin{tabular}{c|c|c|c}
\hline \hline Symb. & Factor & Level 1 & Level 2 \\
\hline A & Welder & Experienced & Inexperienced \\
B & Weld. speed [cm/min] & 20 & 30 \\
C & Current [A] & 90 & 110 \\
D & Electrode type & Rutile & Cellulosic
\end{tabular}

TABLE II

Chemical composition of Grade A, rutile and basic covered electrodes [wt.\%].

\begin{tabular}{c|c|c|c|c|c}
\hline \hline Material/Electrode & $\mathrm{C}$ & $\mathrm{Mn}$ & $\mathrm{Si}$ & $\mathrm{P}$ & $\mathrm{S}$ \\
\hline Grade A & 0.14 & 0.67 & 0.22 & 0.011 & 0.012 \\
Rutile electrode & 0.07 & 0.5 & 0.3 & - & - \\
Cellulosic electrode & 0.012 & 0.5 & 0.14 & - & -
\end{tabular}

\section{Results and discussion}

After the welding experiments were realized according to L8 Taguchi design, fume accumulation on filters was weighed and FFR was calculated. Table III presents Taguchi design and FFR measurements. Experimental data were analyzed using signal to noise $(\mathrm{S} / \mathrm{N})$ ratio and the analysis of variance (ANOVA) methods, using Minitab 17 software. It is better to have smaller fume formation rate in welding, in terms of environmentally friendliness and occupational safety and health. Thus the smaller-isbetter equation was chosen (Eq. 1) in $\mathrm{S} / \mathrm{N}$ calculations. Here, $n$ is the number of repeated experiments, $Y$ is the measured value of the response variable.

$$
\mathrm{S} / \mathrm{N}=-10 \log \left(\frac{\sum Y^{2}}{n}\right) \text {. }
$$

Table IV shows response table for $\mathrm{S} / \mathrm{N}$ ratios. $\mathrm{S} / \mathrm{N}$ ratios in Taguchi method are used to investigate the significance of the factors. Higher $\mathrm{S} / \mathrm{N}$ ratios yield to the desired aim, which is the lower FFR in this study. S/N ratios in Fig. 1 and Table IV show, that electrode type has the highest effect and it is followed by current intensity. Welder's ability ranks as the third, whereas welding speed ranks as the fourth factor. It can clearly be seen in Fig. 1, that FFR is at minimum for first level of welder (A1), second level of welding speed (B2), first level of current (C1) and first level of electrode type (D1). Consequently, optimum design parameter combination was found to be A1B2C1D1.

ANOVA analysis was performed to investigate the significance of the factors on FFR. ANOVA results were based on general linear model and are given in Table $\mathrm{V}$.
TABLE III

L8 experimental set and FFR measurements.

\begin{tabular}{c|c|c|c|c|c}
\hline \hline & \multicolumn{4}{|c|}{ Factors and levels } & Output \\
\hline Run & Welder & $\begin{array}{c}\text { Welding } \\
\text { speed } \\
{\left[\mathrm{cm} \mathrm{min}^{-1}\right]}\end{array}$ & $\begin{array}{c}\text { Current } \\
{[\mathrm{A}]}\end{array}$ & $\begin{array}{c}\text { Electrode } \\
\text { type }\end{array}$ & $\begin{array}{c}\mathrm{FFR}^{-1} \\
{\left[\mathrm{~g} \mathrm{~min}^{-1}\right]}\end{array}$ \\
\hline 1 & 1 & 1 & 1 & 1 & 0.118 \\
2 & 1 & 1 & 2 & 2 & 0.491 \\
3 & 1 & 2 & 1 & 2 & 0.405 \\
4 & 1 & 2 & 2 & 1 & 0.164 \\
5 & 2 & 1 & 1 & 2 & 0.453 \\
6 & 2 & 1 & 2 & 1 & 0.212 \\
7 & 2 & 2 & 1 & 1 & 0.132 \\
8 & 2 & 2 & 2 & 2 & 0.550
\end{tabular}

TABLE IV

Response table for $\mathrm{S} / \mathrm{N}$ ratios.

\begin{tabular}{c|c|c|c|c}
\hline \hline Level & $\mathrm{A}$ & $\mathrm{B}$ & $\mathrm{C}$ & $\mathrm{D}$ \\
\hline 1 & 12.084 & 11.275 & 12.716 & 16.335 \\
2 & 10.773 & 11.582 & 10.141 & 6.523 \\
Delta & 1.310 & 0.307 & 2.574 & 9.812 \\
Rank & 3 & 4 & 2 & 1
\end{tabular}

$P$-value should be equal or less than 0.05 with $95 \%$ confidence level. $P$-values for welder (A), current (C) and electrode type (D) factors were less than 0.05, whereas $P$-value was higher for welding speed (B) factor. Therefore, welder, current and electrode type factors had statistically significant effect on FFR. $F$ values in variance analysis should exceed critical $F$ values obtained from $F$ distribution table [24], in order to be significant according to null hypothesis. $F_{0.05,1,3}=10.1$ for $95 \%$ confidence level. $F$-value for welding speed was less than $F_{0.05,1,3}$, which means that this factor had insignificant effects on FFR.

Since welding speed was determined to be a highly insignificant factor, pooling for welding speed has been realized to clearly see the effects of other factors [27]. Pooled ANOVA results are given in Table VI.

Factor A was evaluated to be statistically significant at least at $95 \%$ confidence level. Similarly, factor C and

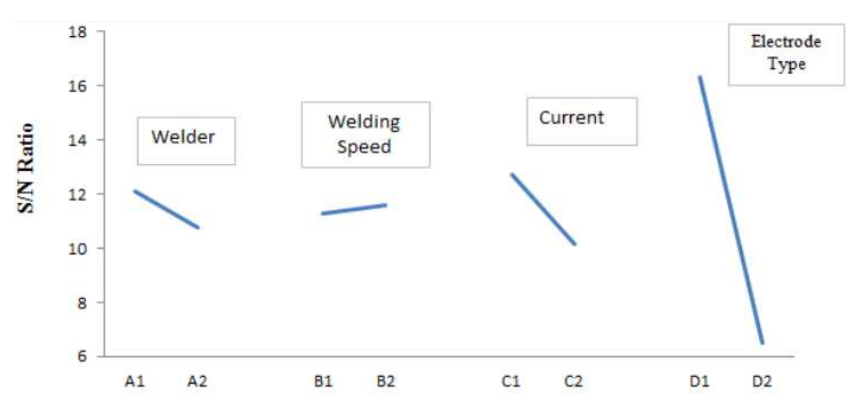

Fig. 1. S/N ratios of factor levels for FFR. 
TABLE V

Analysis of variance results for FFR.

\begin{tabular}{c|c|c|c|c|c}
\hline \hline Source & $\begin{array}{c}\text { Deg. of } \\
\text { freedom }\end{array}$ & Adj. SS & Adj. MS & $F$-value & $P$-value \\
\hline A & 1 & 0.003641 & 0.003641 & 11.99 & 0.041 \\
B & 1 & 0.000067 & 0.000067 & 0.22 & 0.671 \\
C & 1 & 0.011892 & 0.011892 & 39.16 & 0.008 \\
D & 1 & 0.202814 & 0.202814 & 667.80 & 0.000 \\
Error & 3 & 0.000911 & 0.000304 & & \\
Total & 7 & 0.219325 & & &
\end{tabular}

TABLE VI

Pooled ANOVA results.

\begin{tabular}{c|c|c|c|c|c|c}
\hline \hline Source & $\begin{array}{c}\text { Deg. of } \\
\text { freedom }\end{array}$ & Adj. SS & Adj. MS & $F$-value & $P$-value & $\begin{array}{c}\% \\
\text { effect }\end{array}$ \\
\hline A & 1 & 0.003641 & 0.003641 & $14.89^{\&}$ & 0.018 & 1.66 \\
C & 1 & 0.011892 & 0.011892 & $48.65^{\#}$ & 0.002 & 5.42 \\
D & 1 & 0.202814 & 0.202814 & $829.61^{*}$ & 0.000 & 92.47 \\
Error & 4 & 0.000978 & 0.000244 & & & 0.45 \\
Total & 7 & 0.219325 & & & & 100 \\
\hline
\end{tabular}

${ }^{\&}$ At least $95 \%$ confidence, ${ }^{\#}$ at least $99 \%$ confidence,

*at least $99.9 \%$ confidence.

factor D were assessed to be statistically significant at $99 \%$ and $99.9 \%$, respectively. $F_{0.05,1,4}=7.71$ for $95 \%$ confidence level, for pooled results and $F$-values for all of the factors have exceeded $F_{0.05,1,4}$. Percentile effects of welder, current and electrode type were $1.66 \%, 5.42 \%$ and $92.47 \%$, respectively. The effect of the error was $0.45 \%$. Coefficient of determination $(R$-sq (adj.)) in ANOVA analysis was found to be $99.22 \%$.

\section{Confirmation test}

Optimum parameter combination was found to be A1B2C1D1. Since this combination is not included in the L8 Taguchi design, it is crucial to run a confirmation test with this combination. Confirmation test was realized with experienced welder, $90 \mathrm{~A}$ current, $30 \mathrm{~cm} \mathrm{~min}^{-1}$ welding speed and using rutile covered electrode. The obtained fume formation rate was $0.115 \mathrm{~g} \mathrm{~min}^{-1}$, which confirms Taguchi's optimum parameter combination. Since welding speed was a statistically insignificant factor, second level of this factor yielded only a very small amount of reduction in fume formation rate.

\section{Conclusions}

This paper presents an application of Taguchi method to fume formation rate in arc welding with covered electrodes. The results were analyzed using $\mathrm{S} / \mathrm{N}$ ratios and analysis of variance. Results are summarized as follows:

- Optimum condition for fume formation rate was found to be A1B2C1D1, which corresponds to shielded metal arc welding, realized by experienced welder, using rutile-covered electrode with $90 \mathrm{~A}$ current and $30 \mathrm{~cm} \mathrm{~min}^{-1}$ welding speed. Fume formation rate for this optimum condition was found to be $0.115 \mathrm{~g} \mathrm{~min}^{-1}$.

- After ANOVA analysis with 95\% confidence level, welding speed was found to be insignificant factor on fume formation rate and it was pooled. Mert et al. [25] have also shown in their research, that welding speed had very little effect on FFR.

- After pooling in ANOVA analysis, biggest contributor $(\sim 92.5 \%)$ on FFR was reported to be the selection of electrode. Cellulosic electrodes yielded substantially higher fume formation rate compared with rutile ones.

- Current was the second biggest contributor to FFR and had an effect of $\sim 5.5 \%$ in total share. Although current is the only effective factor in fume formation rate for a given electrode type, its share was low in current study. This is because selection of electrode was the dominant factor in this study and therefore there was a small share for other factors.

- Skill of the welder ranked third in the contribution to FFR and was $\sim 1.7 \%$. Even though this share is small, again it is because of the dominant factor of electrode selection and authors believe skill of the welder would be an important factor, because more fluctuations in arc voltage would be expected with the inexperienced welder.

Ship building is known as one of the most complex and labor-intensive manufacturing methods, and it is accepted as heavy industry because of bulky machinery and materials used during dangerous manufacturing processes and hazardous wastes, which emerge from postprocesses and have negative impact not only to the human health but also to the environment. Therefore, the greatest problem in shipyards is the exposure to byproducts of manufacturing processes, particularly of welding and cutting, in terms of occupational safety and health. It is advised that the effect of FFR should be taken into account in the subsequent risk analysis studies. Due to the high preferability of welding, this process is one of the greatest contributors to the formation of such emissions as $\mathrm{CO}_{2}, \mathrm{CO}, \mathrm{NO}_{x}, \mathrm{SO}_{x}, \mathrm{PM}$ and metal particulates. Although the formation of these noxious gases strongly depends on the welding conditions, such as electrode type, current value, type of the base material, welding speed, the ability of the welder etc., they are the inevitable by-products for the most of the welding processes. Accumulation of these gases in the atmosphere causes not only global warming, but also acid rains, which ruin the self-balance of the environment. Despite the fact that the harmful effects of welding fume are well documented, the researches addressing precise negative 
impacts of welding fume on human health continue. Investigation of personal exposure limits for the welders has a great importance for their health. Therefore, studies on welding fume and emissions are the first step to investigate and understand the limits. This study is mainly focused on welding FFR and thus, it has the characteristics of a first stage of a long-term welding experiment. It is believed that the effect of welding on welders' health will be understood more comprehensively with the help of these studies and their application to risk analysis.

\section{Acknowledgments}

This study has been supported by Yildiz Technical University Scientific Research Projects Coordinatorship (Project no: 2013-06-01-GEP01 and Project no: 201310-01-KAP05) and Turk Loydu (Turkish Lloyd).

\section{References}

[1] L. Bilgili, U.B. Celebi, Fresen. Environ. Bull. 24 1054 (2015).

[2] United Nations Conference on Trade and Development (UNCTAD), Review of Maritime Transport, United Nations Publication, Geneva 2015.

[3] K.M. Senoz, L. Bilgili, T. Mert, U.B. Celebi, S. Ekinci, in: 8th Int. Scientific Conference on Naval, Mechanical and Industrial Engineering (TEHNONAV), Constanta, Romania 2015, p. 22.

[4] U.B. Celebi, Fresen. Environ. Bull. 23, 1904 (2014).

[5] A.A. Ennan, S.A. Kiro, M.V. Opyra, V.I. Vishnyakov, J. Aerosol Sci. 64, 103 (2013).

[6] O. Popović, R. Prokić-Cvetković, M. Burzić, U. Lukić, B. Beljić, Renew. Sustain. Enr. Rev. 37, 509 (2014).

[7] B. Kura, S.A. Wisbith, R. Stone, T. Judy, Metal cutting operations: Emission factors for particulates, metals, and metal ions, the emission inventory, Regional strategies for the future proceedings, Raleigh, North Carolina 1999.

[8] R. Mirzaee, A. Allameh, S.B. Mortazavi, A. Khavanin, A. Kazemnejad, M. Akbary, Aur. Nas. Lar. 34, 147 (2007).

[9] W.C. Mener, P.L. Rosen, D.M. Austin, W.S. Holt, in: 10th Int. Emission Inventory Conference-One Atmosphere, One Inventory, Many Challenges, Denver, Colorado 2001.

[10] I. Pires, L. Quintino, R.M. Miranda, Mater. Design. 28, 1623 (2007).
[11] R.T. Deam, S.W. Simpson, J. Haidar, J. Phys. D. Appl. Phys. 33, 1393 (2000).

[12] M. Serageldin, D.W. Reeves, J. Air. Waste. Manag. 59, 619 (2009).

[13] P. Konarski, I. Iwanejko, M. Ćwil, Vacuum 70, 385 (2003).

[14] U.B. Celebi, F.T. Akanlar, N. Vardar, Fresen. Environ. Bull. 18, 1901 (2009).

[15] J.M. Antonini, S. Stone, J.R. Roberts, B. Chen, D. Schwegler-Berry, A.A. Afshari, D.G. Frazer, Toxicol. Appl. Pharm. 223, 234 (2007).

[16] National Institute for Occupational Safety and Health (NIOSH), Nomination of Welding Fumes for Toxicity Studies, 20 February 2002.

[17] A.B. Santamaria, C.A. Cushing, J.M. Antonini, B.L. Finley, F.S. Mowat, J. Tox. Env. Health. 10, 417 (2007).

[18] J.M. Antonini, J.R. Roberts, D. Schwegler-Berry, R.R. Mercer, Ann. Occup. Hyg. 57, 1167 (2013).

[19] B. Kura, P. Mookoni, J. Ship. Prod. 14, 246 (1998).

[20] M. Huvinen, A. Makitie, H. Jarventaus, H. Wolff, T. Stjernvall, A. Hovi, A. Hirvonen, R. Ranta, M. Nurminen, H. Norppa, Mutagenesis 17, 425 (2002).

[21] W. Matczak, J. Chmielnicka, Pol. J. Occup. Med. Environ. Health. 2, 376 (1989).

[22] R.B. Park, M.B. Rosemarie, D.E. Eggerth, E. Diamond, K.J. Spencer, R. Gwiazda, NeuroToxicology 27, 373 (2006).

[23] U.B. Celebi, L. Bilgili, T. Mert, K.M. Senoz, S. Ekinci in: 18th Int. Symp. Environmental Pollution and its Impact on Life in the Mediterranean Region ( $M E$ $S A E P)$, Crete, Greece 2015, p. 60.

[24] G. Taguchi, E.A. Elsayed, T.C. Hsiang, Quality Engineering in Production Systems, McGraw-Hill, New York 1989

[25] T. Mert, L. Bilgili, K.M. Senoz, U.B. Celebi, S. Ekinci, in: Energy, Transportation and Global Warming, Ed. P. Grammelis, Springer, Switzerland 2016, p. 795 .

[26] International Organization for Standardization, EN ISO 15011-1:2009 - Health and safety in welding and allied processes - Laboratory method for sampling fume and gases Part 1: Determination of fume emission rate during arc welding and collection of fume for analysis, (2009).

[27] O. Savas, Steel Comp. Struct. 18, 345 (2015). 